\title{
High expression of cell death-inducing DFFA-like effector a (CIDEA) promotes milk fat content in dairy cows with clinical ketosis
}

\author{
Xudong Sun, ${ }^{1 *}$ Yazhe Wang, ${ }^{1 *}$ Juan J. Loor,${ }^{2 *}$ Ryan Bucktrout,${ }^{2}$ Xin Shu, ${ }^{1}$ Hongdou Jia, ${ }^{1}$ Jihong Dong, ${ }^{1}$ \\ Rankun Zuo, ${ }^{3}$ Guowen Liu, ${ }^{1}$ Xiaobing Li, ${ }^{1}$ and Xinwei $\mathrm{Li}^{1} \dagger$ \\ ${ }^{1}$ Key Laboratory of Zoonosis, Ministry of Education, College of Veterinary Medicine, Jilin University, 5333 Xi'an Road, Changchun, 130062, Jilin, \\ China \\ ${ }^{2}$ Mammalian NutriPhysioGenomics, Department of Animal Sciences and Division of Nutritional Sciences, University of Illinois, Urbana 61801 \\ ${ }^{3}$ College of Veterinary Medicine, Qingdao Agriculture University, Qingdao, 266109, Shandong, China
}

\section{ABSTRACT}

High blood concentrations of nonesterified fatty acids (NEFA) during ketosis represent a source of fatty acids for milk fat synthesis and explain the increase in milk fat content in ketotic cows. Cell death-inducing DFFA-like effector a (CIDEA) is a lipid droplet coat protein with important roles in the regulation of milk fat synthesis and secretion in mice. Whether ketosis alters the expression of CIDEA in mammary gland tissue and the extent to which it may contribute to regulation of milk fat synthesis and secretion are unknown. Mammary gland tissue and blood samples were collected from healthy $(\mathrm{n}=15)$ and clinically ketotic $(\mathrm{n}=15)$ cows. Mammary epithelial cells isolated from cows were infected with CIDEA overexpression adenovirus for 48 $\mathrm{h}$, treated with $0,0.3,0.6$, or $1.2 \mathrm{~m} M$ NEFA for $24 \mathrm{~h}$, or infected with CIDEA-silencing adenovirus for $48 \mathrm{~h}$ and treated with $1.2 \mathrm{~m} M$ NEFA for $24 \mathrm{~h}$. Serum concentrations of NEFA and $\beta$-hydroxybutyrate were greater in cows with clinical ketosis, and milk production and dry matter intake were lower in cows with clinical ketosis. However, compared with healthy cows, the content of milk fat of cows with clinical ketosis was greater. Compared with healthy cows, abundance of mRNA and protein of CIDEA, fatty acid synthase (FASN), acetylcoA carboxylase 1 (ACACA), butyrophilin (BTN1A1), and xanthine dehydrogenase $(\mathrm{XDH})$ was greater in mammary tissue of cows with clinical ketosis. Overexpression of CIDEA in cultured mammary epithelial cells increased the abundance of FASN, ACACA, XDH, and BTN1A1, and increased triacylglycerol (TAG) content in mammary epithelial cells. Exogenous NEFA

Received July 25, 2018.

Accepted October 22, 2018.

*These authors contributed equally to this study.

†Corresponding author: lixinwei100@126.com increased the abundance of CIDEA, FASN, ACACA, $\mathrm{XDH}$, and BTN1A1, and increased TAG content in mammary epithelial cells. Importantly, knockdown of CIDEA reversed the upregulation of FASN, ACACA, $\mathrm{XDH}$, and BTN1A1 abundance and TAG content induced by NEFA treatment. Overall, these data suggest that high levels of NEFA stimulate the expression of CIDEA and enhance de novo fatty acid synthesis and milk fat secretion. As such, these mechanisms explain in part the elevation of milk fat content in dairy cows with clinical ketosis.

Key words: CIDEA, milk fat, mammary epithelial cell, dairy cow

\section{INTRODUCTION}

Ketosis is a major metabolic disease of dairy cows in early lactation. This disease is manifested by a gradual decrease in milk production (Ospina et al., 2010) with a concurrent increase in milk fat percentage and a decrease in milk protein percentage (Duffield et al., 2009). Body fat mobilization due to negative energy balance in early lactation results in increased plasma concentrations of nonesterified fatty acids (NEFA) in dairy cows (Gross et al., 2013). Excessive NEFA absorbed by liver from plasma are metabolized into ketone bodies (acetoacetate, BHB, and acetone) in hepatocytes, thereby inducing ketosis (White, 2015). High concentrations of circulating NEFA in ketotic cows are a significant contributor to milk fat synthesis in the mammary gland (Adewuyi et al., 2005; Palmquist et al., 2006). In ruminants, circulating lipoproteins and NEFA are taken up by the mammary gland and directly used for milk fat synthesis (Glascock and Welch, 1974). Importantly, milk fat concentration is positively correlated with plasma NEFA concentration (Pullen et al., 1989). Li et al. (2014a) found that stearic acid promoted triacylglycerol (TAG) synthesis in dairy cow mammary epithelial cells. Furthermore, the decrease in 
energy intake during ketosis increased plasma concentrations of NEFA, including oleic acid, linoleic acid, palmitic acid, stearic acid, and palmitoleic acid, which were associated with an increase of milk fat content (Yamdagni and Schultz, 1970; Duffield et al., 2009). Besides the greater availability of exogenous NEFA for esterification into TAG within mammary cells, the precise molecular mechanisms controlling the response in milk during ketosis are unknown.

Milk lipid synthesis is a complex process and is highly regulated by changes in gene expression. The cell deathinducing DNA fragmentation factor- $\alpha$-like effector a (CIDEA) protein is a lipid droplet-associated protein that is highly expressed in adipose tissue (Zhou et al., 2003). High levels of CIDEA expression were detected in the mouse mammary gland during lactation and were associated with lipid secretion (Wang et al., 2012). In tissues such as adipose and liver, CIDEA seems to play a key role in the regulation of fatty acid synthase (FASN) and acetyl-coA carboxylase 1 (ACACA; Qi et al., 2008; Zhou et al., 2012). Furthermore, several lipogenic enzymes (FASN, ACACA, diacylglycerol acyltransferase) and CIDEA are markedly upregulated after parturition in bovine mammary tissue (Bionaz and Loor, 2008; Bionaz et al., 2012a,b). Thus, we hypothesized that CIDEA may play an important role in regulation of milk fat synthesis in cows.

Lipid synthesis and secretion are important steps in the formation of milk fat. Lipid synthesis is a complex biological process that is partly regulated by gene expression (Bionaz et al., 2012b). For instance, relative to the dry period, FASN and ACACA are markedly upregulated in the dairy cow mammary epithelium at the onset of lactation (Bionaz and Loor, 2008). Specific proteins that surround the lipid droplet are required for milk lipid secretion (Heid and Keenan, 2005). Expression of butyrophilin (BTN1A1) is necessary for secretion of milk lipid droplets (Ogg et al., 2004). Xanthine dehydrogenase (XDH) is localized to the apical membrane of mammary epithelial cells and interacts with the cytoplasmic domain of BTN1A1 when secretion is activated (Ishii et al., 1995). As crucial mediators of milk lipid secretion, relative to the dry period, $\mathrm{XDH}$ and BTN1A1 expression in the mammary glands are markedly upregulated at the onset of lactation in dairy cows (Bionaz and Loor, 2008; Jedrzejczak and Szatkowska, 2014). Therefore, those studies demonstrated that de novo lipogenesis as well as XDH and BTN play crucial roles in formation of milk fat in bovine mammary epithelial cells. Because CIDEA plays important roles in the regulation of milk fat synthesis in mice, we hypothesized that it may also mediate alterations in milk fat synthesis and secretion caused by increased fatty acid uptake by mammary gland of dairy cows as it occurs during ketosis.

\section{MATERIALS AND METHODS}

The study protocol was approved by the Ethics Committee for the Use and Care of Animals, Jilin University (Changchun, China). The animal studies were performed in accordance with the Guiding Principles of Animals adopted by the Chinese Association for Laboratory Animal Sciences (http://www.calas.org.cn/ index.php? $\mathrm{m}=$ content $\& \mathrm{c}=$ index $\& \mathrm{a}=$ show $\&$ catid $=50 \&$ id $=670)$.

\section{Animals}

Dairy cows were selected from a 7,000-cow dairy farm located in Changchun City, Jilin Province, China. Cows were housed in a climate-controlled barn in individual tiestalls to reduce environmental effects. All cows received a routine physical examination to ensure absence of other co-morbidities. We chose lactating Holstein cows with similar numbers of lactations (median $=3$, range $=2$ to 4 ) and DIM (median $=6 \mathrm{~d}$, range $=3$ to $10 \mathrm{~d}$ ). Veterinarians classified cows as clinically ketotic if feed intake, milk yield, or both were reduced and a nitroprusside test for ketone bodies in milk was positive (Du et al., 2018a). Accordingly, we preselected 40 cows suspected of being clinically ketotic and 50 healthy cows. Subsequently, the blood concentration of BHB in these cows was measured. According to the clinical symptoms and serum BHB concentration (Itle et al., 2015; Du et al., 2018a), 15 clinically ketotic cows with serum BHB concentration higher than $3 \mathrm{mM}$ and 15 control cows with serum BHB concentration less than $0.6 \mathrm{~m} M$ were randomly selected. The basic description of the cows is shown in Table 1. Cows had ad libitum access to the same diet (Supplemental Table S1; https: //doi.org/10.3168/jds.2018-15439) that was offered twice a day (0830 and $1600 \mathrm{~h})$. Diet samples were collected twice daily at each feeding on 5 consecutive days, encompassing $3 \mathrm{~d}$ before biopsy through $2 \mathrm{~d}$ postbiopsy. Nutrient composition of forage was determined on a 6500 NIR spectrophotometer (Foss North America, Eden Prairie, MN) using equations of the NIRS Consortium (Lundberg et al., 2004).

Cows had access to a constant supply of fresh water and were milked twice daily at 0800 and $1530 \mathrm{~h}$. Milk yield was electronically recorded and milk samples were collected at each milking for $5 \mathrm{~d}$ and stored at $4^{\circ} \mathrm{C}$ with a preservative ( $1 \mathrm{mg} / \mathrm{mL}$ of potassium dichromate). To take into consideration the daily variation in milk yield as well as the effect of tissue biopsy on milk produc- 
tion, data from the $3 \mathrm{~d}$ before biopsy were averaged with data from $2 \mathrm{~d}$ postbiopsy, disregarding production data from both the day of biopsy and the first day postbiopsy. This was deemed necessary because the biopsy procedure typically leads to a reduction in milk yield for the first 2 to 3 milkings (Farr et al., 1996). Milk composition was analyzed as described previously (Loor and Herbein, 2003). Milk fat, protein, and lactose were analyzed by infrared analysis with a 4-channel spectrophotometer (Multispec, Foss North America).

Blood samples were collected from the jugular vein before feeding and centrifuged at 3,000 $\times g$ for $15 \mathrm{~min}$ at $4^{\circ} \mathrm{C}$ to obtain serum. Concentrations of glucose, $\mathrm{BHB}$, and NEFA in serum were determined using a Hitachi 7170 autoanalyzer (Hitachi, Tokyo, Japan) with commercially-available kits (BHB: Cat No RB1008; NEFA: Cat. No. FA115; glucose: Cat No GL3815; Randox Laboratories, Crumlin, UK). Percutaneous biopsies from 15 cows with clinical ketosis and 15 healthy cows were obtained from the right or left rear quarter of the mammary gland according to published procedures (Bionaz and Loor, 2008). Biopsies were conducted at $0800 \mathrm{~h}$ (after morning milking). Briefly, after making the skin incision, we performed blunt dissection of the mammary capsule to ensure tissue obtained during the biopsy was mammary parenchyma. Immediately after removal of the biopsy instrument from the capsule, pressure was applied to the wound until visual signs of bleeding were absent. The skin incision was closed with 4 or 5 Michel clips (11 mm; Henry Schein, Melville, NY). The incision site was sprayed with topical antiseptic (povidone iodine ointment, 10\%; Taro Pharmaceuticals, Hawthorne, NY). Health was monitored postsurgery by recording rectal temperature, milk yield, and feed intake daily for $7 \mathrm{~d}$. Surgical clips were removed $7 \mathrm{~d}$ postbiopsy. No incidence of mastitis was detected for any cow during the $7 \mathrm{~d}$ after surgery. Tissue samples for quantitation of protein and RNA were frozen immediately in liquid nitrogen and stored at $-80^{\circ} \mathrm{C}$ until analysis.

\section{Primary Cell Culture}

Primary mammary epithelial cells from 3 lactating dairy cows were harvested as described previously (Wang et al., 2014, 2017). Milk yield, milk fat, milk protein, and milk lactose of cows averaged $32.5 \pm 1.9$ $\mathrm{kg} / \mathrm{d}, 4.25 \pm 0.02 \%, 3.18 \pm 0.03 \%$, and $4.75 \pm 0.02 \%$, respectively (mean \pm SEM). These cows were slaughtered at 90 DIM. Immediately after exsanguination, parenchyma samples were aseptically removed from the core of the mammary gland. The tissues were sliced to pieces and digested with $0.5 \%$ collagenase III (C8490, Solarbio, Beijing, China) for $3 \mathrm{~h}$ at $38^{\circ} \mathrm{C}$. The solution was filtered sequentially with a $74-\mu \mathrm{m}$ strainer and centrifuged at $150 \times g$ for $10 \mathrm{~min}$ at $4^{\circ} \mathrm{C}$. The cells were cultured in Dulbecco's modified Eagle's medium: Nutrient Mixture F-12 medium (DMEM/F-12, Grand Island, New York, NY) supplemented with $10 \%$ fetal bovine serum (Grand Island), $500 \mathrm{ng} / \mathrm{mL}$ of hydrocortisone (Sigma-Aldrich, St. Louis, MO), $1 \mu \mathrm{g} / \mathrm{L}$ of prolactin (Sigma-Aldrich), $10 \mathrm{ng} / \mathrm{mL}$ of epidermal growth factor (Peprotech, Rocky Hill, NJ), and $100 \mathrm{IU} / \mathrm{mL}$ of penicillin/streptomycin (Baoman Biotechnology, Shanghai, China) for $48 \mathrm{~h}$ at $37^{\circ} \mathrm{C}$ under an atmosphere containing $5 \% \mathrm{CO}_{2}$. The cells were then digested with trypsin (a 3-min digestion followed by a 5-min digestion) to purify the epithelial cells. After passaging 3 times, the cells were seeded into a 6 -well tissue culture plate $(2$ $\mathrm{mL} /$ well) with DMEM/F-12 supplemented with $10 \%$ fetal bovine serum and $100 \mathrm{IU} / \mathrm{mL}$ of penicillin/streptomycin. Medium was changed once every $24 \mathrm{~h}$.

\section{NEFA Treatment and Adenovirus Transfections}

The NEFA mixture was prepared according to a previous study (Du et al., 2018a), diluted in $0.1 \mathrm{M} \mathrm{KOH}$ at $60^{\circ} \mathrm{C}$, and the $\mathrm{pH}$ of the solution was adjusted to 7.4 with hydrochloric acid $(1 M)$. The NEFA stock $(52.7$ $\mathrm{m} M)$ solution included oleic acid $(22.9 \mathrm{mM})$, linoleic acid $(2.6 \mathrm{mM})$, palmitic acid $(16.8 \mathrm{mM})$, stearic acid

Table 1. The basic description of healthy and clinically ketotic cows

\begin{tabular}{|c|c|c|c|c|c|}
\hline Item & \multicolumn{2}{|c|}{ Clinical ketosis $(\mathrm{n}=15)$} & \multicolumn{2}{|c|}{ Control $(\mathrm{n}=15)$} & $P$-value \\
\hline Milk production ( $\mathrm{kg}$ of milk/cow per day) & 25.1 & $23.1,27.3$ & 31.3 & $29.5,34.3$ & 0.0435 \\
\hline Milk fat $(\mathrm{kg} / \mathrm{d})$ & 1.31 & $1.15,1.43$ & 0.88 & $0.75,1.02$ & 0.0426 \\
\hline Milk protein $(\mathrm{kg} / \mathrm{d})$ & 0.617 & $0.542,0.754$ & 1.04 & $0.91,1.15$ & 0.0176 \\
\hline Serum glucose $(\mathrm{m} M)$ & 2.09 & $1.99,2.21$ & 4.14 & $4.04,4.19$ & 0.0054 \\
\hline Serum nonesterified fatty acids $(\mathrm{m} M)$ & 1.24 & $1.17,1.31$ & 0.24 & $0.21,0.28$ & 0.0091 \\
\hline Serum BHB $(\mathrm{m} M)$ & 3.82 & $3.6,4.17$ & 0.46 & $0.38,0.52$ & 0.0071 \\
\hline
\end{tabular}


(7.6 $\mathrm{mM})$, and palmitoleic acid $(2.8 \mathrm{mM})$. The mammary epithelial cells were cultured with $0,0.3,0.6$, or $1.2 \mathrm{~m} M$ NEFA for $24 \mathrm{~h}$ and $2 \%$ fatty acid-free BSA for $24 \mathrm{~h}$. Mammary cells take up fatty acids from BSAbound NEFA (Bionaz and Loor, 2008); thus, the cells were cultured with NEFA and $2 \%$ BSA.

The empty adenovirus vectors-green fluorescent protein (Ad-GFP), CIDEA overexpression adenovirus (Ad-CIDEA), and CIDEA silence adenovirus (AdshCIDEA) were constructed by Hanbio (Shanghai, China). Briefly, to construct the CIDEA expression plasmid, full-length bovine CIDEA was amplified from mammary tissue cDNA using PCR and subcloned into the pcDNA3.1 $(+)$ vector (Invitrogen, Carlsbad, CA). The following PCR primer pair was used: forward 5'-AGAGGATCCATGGAGACTGCCCGGGACTGCG-3'; reverse 5'-TCTGAATTCCTACCCTCTCTTGATCCCTCT-3'. The integrity of plasmid DNA was verified by DNA sequencing. To construct the short hairpin RNA (shRNA) plasmid for targeting CIDEA, a pair of oligonucleotides specific for the bovine CIDEA sequence were chemically synthesized and subcloned into the BamHI/HindIII sites of pSilencer 3.1-H1 (Ambion, Carlsbad, CA). The shRNA sequence was 5'GCTTCTCAGCAAGACCTTGGA3'. The shRNA sequence was designed based on the CIDEA gene-specific coding region as the sense strand. Subsequently, the plasmids capable of increasing or decreasing the expression of CIDEA were directly subcloned into the pHBAd-MCMV-MCS-CMV-EGFP vector (Hanbio). We then transfected adenoviral vectors into 293 cells to amplify and collect the virus. The titer of virus reached $10^{10} \mathrm{pfu}$ (plaque-forming units) $/ \mathrm{mL}$. For the transfection experiments, to overexpress CIDEA the cells were treated with the overexpression adenovirus for $48 \mathrm{~h}$. To silence CIDEA, the cells were treated with the silencing adenovirus for $48 \mathrm{~h}$, cells were then treated with 1.2 $\mathrm{m} M$ NEFA for another $24 \mathrm{~h}$. Cell culture experiments as indicated were performed in triplicate.

\section{Quantitative Reverse-Transcription PCR Assay}

Quantitative reverse-transcription PCR was performed as described previously (Du et al., 2017). Total RNA from mammary tissues and cultured mammary epithelial cells were extracted using Trizol (Invitrogen) according to the supplier's protocol (https://assets .thermofisher.com/TFS-Assets/LSG/manuals/trizol _reagent.pdf). The RNA concentration and quality were measured using K5500 MicroSpectrophotometer (Beijing Kaiao Technology Development Ltd., Beijing, China) and electrophoresis (1\% agarose gels). According to Minimum Information for Publication of Quantitative Real-Time PCR Experiment (MIQE) guidelines (http://www.rdml.org/clinchem.2008.112797v1.pdf), a range of 1.8 to 2.0 of $\mathrm{OD}_{260} / \mathrm{OD}_{280}$ (the optical density ratio at 260 and $280 \mathrm{~nm}$ ) ratio is an adequate threshold for determining the purity of RNA upon extraction of biologic samples. In our study, the $\mathrm{OD}_{260} / \mathrm{OD}_{280}$ ratio of the total RNA was determined to be 1.9 and met the specified purity requirements. One microgram of total RNA was then reverse-transcribed to cDNA (TaKaRa Biotechnology Co. Ltd., Tokyo, Japan) in accordance with the manufacturer's instructions (Jia et al., 2019). The mRNA abundance was detected using a SYBR green plus reagent kit (TaKaRa Biotechnology Co. Ltd.) with the 7500 Real-Time PCR System (Applied Biosystems, Foster City, CA). The conditions were initial denaturation at $94^{\circ} \mathrm{C}$ for $2 \mathrm{~min}, 35$ cycles of amplification (denaturation at $94^{\circ} \mathrm{C}$ for $10 \mathrm{~s}$, annealing at $60^{\circ} \mathrm{C}$ for $15 \mathrm{~s}$, and extension at $72^{\circ} \mathrm{C}$ for $30 \mathrm{~s}$ ) and extension at $72^{\circ} \mathrm{C}$ for $5 \mathrm{~min}$. Primer sets are reported in Supplemental Table S2 (https://doi.org/10.3168/jds .2018-15439). The cycle-to-threshold values of GAPDH, ubiquitin, and $\beta$-actin were not affected by the different experimental treatments (Supplemental Figure S1; https://doi.org/10.3168/jds.2018-15439); therefore, the relative expression of target genes was normalized to the mean of GAPDH, ubiquitin, and $\beta$-actin. The relative expression of target genes was determined by the $2^{-\Delta \Delta \mathrm{CT}}$ method. For in vivo quantitative reversetranscription PCR experiments, the PCR reaction was performed in triplicate for each sample $(\mathrm{n}=15$ cows per group). For in vitro quantitative reverse-transcription PCR experiments, the PCR reactions were performed in triplicate from each of the 3 individual cell preps.

\section{Protein Extraction and Western Blotting}

Western blotting assays were performed as described by Sun et al. (2017). Total protein of mammary tissue and cultured mammary epithelial cells was extracted using a commercial protein extraction kit (Sangon Biotech Co. Ltd., Shanghai, China) according to the manufacturer's instructions (http://www.sangon.com/ productImage/DOC/C510003/C510003_ZH_P.pdf). Protein content was quantified by the BCA Protein Assay Kit (P1511; Applygen Technologies, Beijing, China) according to the manufacturer's instructions (http://www.applygen.com/product/danbai/\%E8 \%9B\%8B\%E7\%99\%BD \%E5\%AE\%9A \%E9\%87\%8F/ 96.html). The protein (30 $\mu \mathrm{g} / \mathrm{lane})$ was separated in SDS-PAGE and electro-transferred onto polyvinylidene fluoride membranes $(0.45 \mu \mathrm{m})$. Then, the polyvinylidene fluoride membranes were blocked with $3 \%$ BSA in Tris-HCL (0.05 $M$ Tris, pH 7.4, $0.2 \mathrm{M} \mathrm{NaCl}$ ) buffer solution containing 0.1\% Tween-20 (V900548; Beijing Dingguo Changsheng Biotech Co. Ltd., Beijing, China) 
for $4 \mathrm{~h}$ at room temperature. The blocked membranes were incubated overnight at $4^{\circ} \mathrm{C}$ with specific antibodies for CIDEA (1:500, ab62343; Abcam, Cambridge, UK), FASN (1:500, C20G5; CST, Danvers, MA), ACACA (1:1000, ab45174; Abcam), BTN1A1 (1:1000, ab180605; Abcam), XDH (1:500, sc-398548; Santa Cruz Biotechnology, Santa Cruz, CA), and $\beta$-actin (internal control; 1:1000, sc-47778; Santa Cruz, CA). Subsequently, the polyvinylidene fluoride membranes were incubated with horseradish peroxidase-conjugated anti-mouse or anti-rabbit antibody (1:5,000, Boster, Wuhan, China) at room temperature for $45 \mathrm{~min}$. Immunoreactive bands were detected using an enhanced chemiluminescence solution (Pierce Biotechnology Inc., Chicago, IL). The bands were visualized using a protein simple imager (ProteinSimple, San Jose, CA).

\section{TAG Content Determination}

The TAG content was detected as described by Ding et al. (2012) and Du et al. (2018b). Briefly, TAG content in cells and supernatant was determined using commercial kits (E1003, E1013, Applygen Technologies Inc.). The cell-free supernatant $(1 \mathrm{~mL})$ in each group was collected following treatments. Hepatocytes were harvested and washed twice with ice-cold PBS. Subsequently, cells were lysed with lysis buffer (Sangon Biotech Co. Ltd.) in an ice bath. The lysate was centrifuged at $12,000 \times g$ at $4^{\circ} \mathrm{C}$ for $5 \mathrm{~min}$ and the supernatant collected. A portion of the supernatant was used to determine total protein concentrations using the bicinchoninic acid assay (P1511, Applygen Technologies Inc.). The remaining supernatant was heated in a water bath $\left(70^{\circ} \mathrm{C}\right)$ for $10 \mathrm{~min}$, and centrifuged at $800 \times$ $g$ for 5 min at room temperature. A $10-\mu \mathrm{L}$ supernatant was then mixed with $190 \mu \mathrm{L}$ of chromogenic liquid before measuring TAG. A $30-\mu \mathrm{L}$ sample from the cell-free supernatant was mixed with $170 \mu \mathrm{L}$ of chromogenic liquid before measuring TAG assay. The absorbance at $550 \mathrm{~nm}$ is proportional to the concentration of TAG.

\section{Oil Red O Staining}

The bovine mammary epithelial cells were grown on glass coverslips to $90 \%$ confluence and treated with NEFA and adenovirus as described above. The coverslips were then twice washed with ice-cold PBS. Cells were then fixed in $10 \%$ formalin for $15 \mathrm{~min}$. Next, the cells were twice washed with ice-cold PBS and then with $60 \%$ (vol/vol) isopropanol for $2 \mathrm{~min}$, stained with $0.5 \%$ (wt/vol) Oil Red O solution for $15 \mathrm{~min}$, washed briefly with $60 \%$ isopropanol and subsequently with ice-cold PBS, and then counter-stained with hematoxylin before microscopy.

\section{Statistical Analysis}

All data are expressed as the mean \pm standard error of the means. Statistical analyses were performed using GraphPad Prism 5 (GraphPad InStat Software, San Diego, CA). In the in vivo studies, data from quantitative reverse-transcription PCR and Western blotting were normally distributed and analyzed with paired $t$-tests, other data were non-normally distributed and analyzed with Wilcoxon signed rank test. In the in vitro studies, comparisons among groups were analyzed using the one-way ANOVA with subsequent Bonferroni correction. We considered $P<0.05$ statistically significant and $P<0.01$ highly significant.

\section{RESULTS}

\section{Baseline Characteristics and Blood Parameters}

Milk production and DMI of cows with clinical ketosis was lower $(P<0.05)$ than healthy cows (Table $1)$. The content of milk protein in cows with clinical ketosis was lower $(P<0.05)$ than healthy cows (Table 1 ); however, milk fat content of cows with clinical ketosis was greater $(P<0.05)$ than healthy cows (Table $1)$. Concentrations of NEFA and BHB were greater $(P$ $<0.01)$ in cows with clinical ketosis than healthy cows (Table 1). In contrast, concentration of glucose was markedly lower $(P<0.01)$ in cows with clinical ketosis than healthy cows (Table 1$)$.

\section{Increased Protein and mRNA Abundance in Mammary Tissue of Clinically Ketotic Cows}

Abundance of mRNA of CIDEA, FASN, ACACA, $X D H$, and BTN1A1 was greater $(P<0.01)$ in mammary glands of cows with clinical ketosis than healthy cows (Figure 1A). Similarly, the protein abundance of CIDEA, FASN, ACACA, XDH, and BTN1A1 was greater $(P<0.05$ and $P<0.01)$ in mammary gland of cows with clinical ketosis than healthy cows (Figure $1 \mathrm{~B}$ and $\mathrm{C})$.

\section{Overexpression of CIDEA Increased Fatty Acid Synthesis and Milk Fat Secretion}

The mRNA and protein abundance of CIDEA in the Ad-CIDEA group was greater $(P<0.01)$ than the control group (Figure 2A, B, and C). Furthermore, CIDEA overexpression markedly upregulated the mRNA and protein abundance of FASN, ACACA, XDH, and BTN1A1 (Figure 2A, B, and C; $P<0.01$ ). Subsequently, a significant increase of lipid accumulation and TAG content in mammary epithelial cells (Figure 2D and E; 

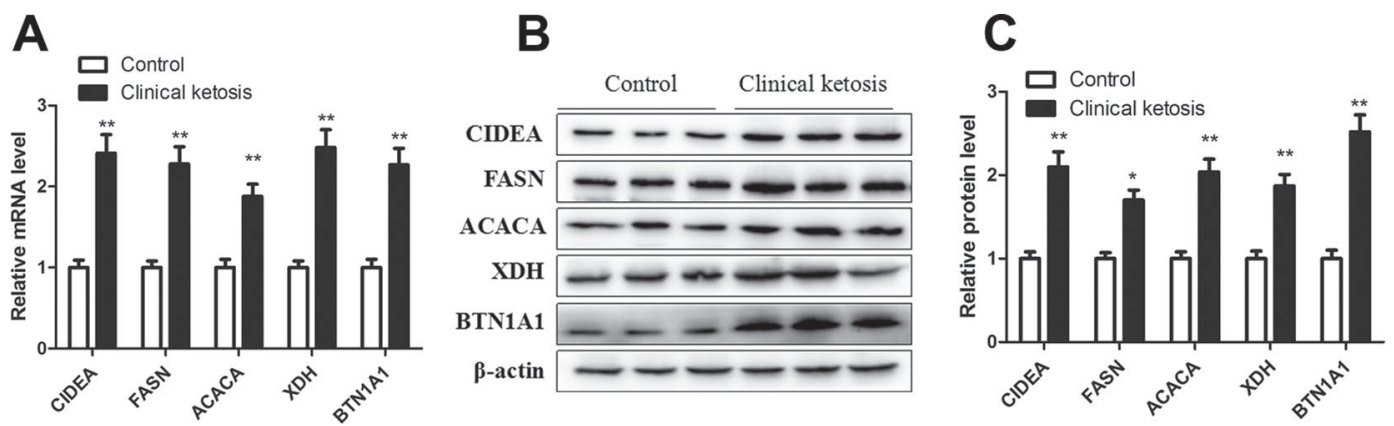

Figure 1. Abundance of CIDEA, FASN, ACACA, XDH, and BTN1A1 was increased in mammary gland of clinical ketotic cows. (A) Relative mRNA abundance of CIDEA, FASN, ACACA, XDH, and BTN1A1. (B) Western blot analysis of CIDEA, FASN, ACACA, XDH, and BTN1A1. (C) Relative protein abundance of CIDEA, FASN, ACACA, XDH, and BTN1A1. The data of the control group were used to normalize the data of the cows with clinical ketosis group. The data were analyzed with paired $t$-tests and expressed as the mean \pm SEM (n $=15$ per group). ${ }^{*} P$ $<0.05,{ }^{* *} P<0.01$.

$P<0.01$ ) and supernatant (Figure $2 \mathrm{~F} ; P<0.01$ ) was observed in the Ad-CIDEA group.

\section{Fatty Acid Synthesis and Milk Fat Secretion are Enhanced by NEFA}

Bovine mammary epithelial cells were treated with different concentrations of NEFA, which resulted in a dose-dependent increase in the mRNA abundance of CIDEA, FASN, ACACA, XDH, and BTN1A1, with significantly greater levels in the 0.6 and $1.2 \mathrm{~m} M$ NEFA treatment groups as compared with the control group (Figure 3A; $P<0.05$ and $P<0.01$ ). Similarly, compared with the control group, protein abundance of CIDEA, FASN, ACACA, XDH, and BTN1A1 also was greater in the 0.6 and $1.2 \mathrm{~m} M$ NEFA-treated groups (Figure 3B and C; $P<0.05$ and $P<0.01$ ). Furthermore, both Oil Red $\mathrm{O}$ staining and TAG quantification results showed a significant increase of lipid accumulation in mammary epithelial cells in the 0.6 and $1.2 \mathrm{mM}$ NEFA-treated groups (Figure 3D and E; $P<0.01$ ). The TAG content in the supernatant was also greater in the 0.6 and $1.2 \mathrm{mM}$ NEFA-treated groups (Figure $3 \mathrm{~F} ; P<0.05$ and $P<0.01)$.

\section{Effects of Knockdown of CIDEA}

Silencing of CIDEA with adenovirus (Ad-shCIDEA) decreased the mRNA and protein abundance of CIDEA (Figure 4A-C; $P<0.01$ ) in mammary epithelial cells. In addition, it markedly alleviated the increase in mRNA and protein abundance of FASN, ACACA, $\mathrm{XDH}$, and BTN1A1 induced by NEFA (Figure 4A-C; $P<0.01)$. Oil Red $\mathrm{O}$ staining and TAG quantification results showed that CIDEA knockdown significantly attenuated the elevation of lipid accumulation and TAG content in mammary epithelial cells (Figure 4D and E,
$P<0.01)$ induced by NEFA. The knockdown of $C I$ $D E A$ also alleviated the increase of TAG content in the supernatant (Figure 4F, $P<0.01$ ) induced by NEFA.

\section{DISCUSSION}

In dairy cows with ketosis, the NEFA from mobilization of body fat represent a major source of milk fat precursors (Bauman and Griinari, 2000). The protein CIDEA promotes synthesis and secretion of lipid in the mouse mammary gland during lactation (Wang et al., 2012). Furthermore, high abundance of CIDEA in mammary tissue of lactating dairy cows implied that this protein may also be involved in the synthesis and secretion of lipid in the bovine mammary gland (Yonezawa et al., 2009). In our study, CIDEA abundance was increased significantly in mammary gland of cows with clinical ketosis, and our in vitro data revealed that NEFA work through CIDEA to increase milk fat synthesis and secretion in mammary epithelial cells. As such, that effect can partly explain the elevation of milk fat content in dairy cows with clinical ketosis.

Milk fat synthesis and secretion are complex processes regulated in part by changes in gene expression. Thus, elevation of milk fat content in cows with clinical ketosis may be associated with alteration in lipogenic genes. In ruminants, about one-half of the milk fatty acids are derived from de novo synthesis (Bauman and Griinari, 2000). Key enzymes regulating de novo fatty acid synthesis are FASN and ACACA (Torrens et al., 2014; Petrov et al., 2015); FASN performs the majority of the enzymatic steps during fatty acid synthesis, whereas ACACA is a rate-limiting enzyme in fatty acid synthesis and converts acetyl-CoA to malonyl-CoA. The transcription of these genes is activated at the onset and throughout lactation in dairy cows (Bionaz and Loor, 2008). Furthermore, XDH and BTN1A1 are 

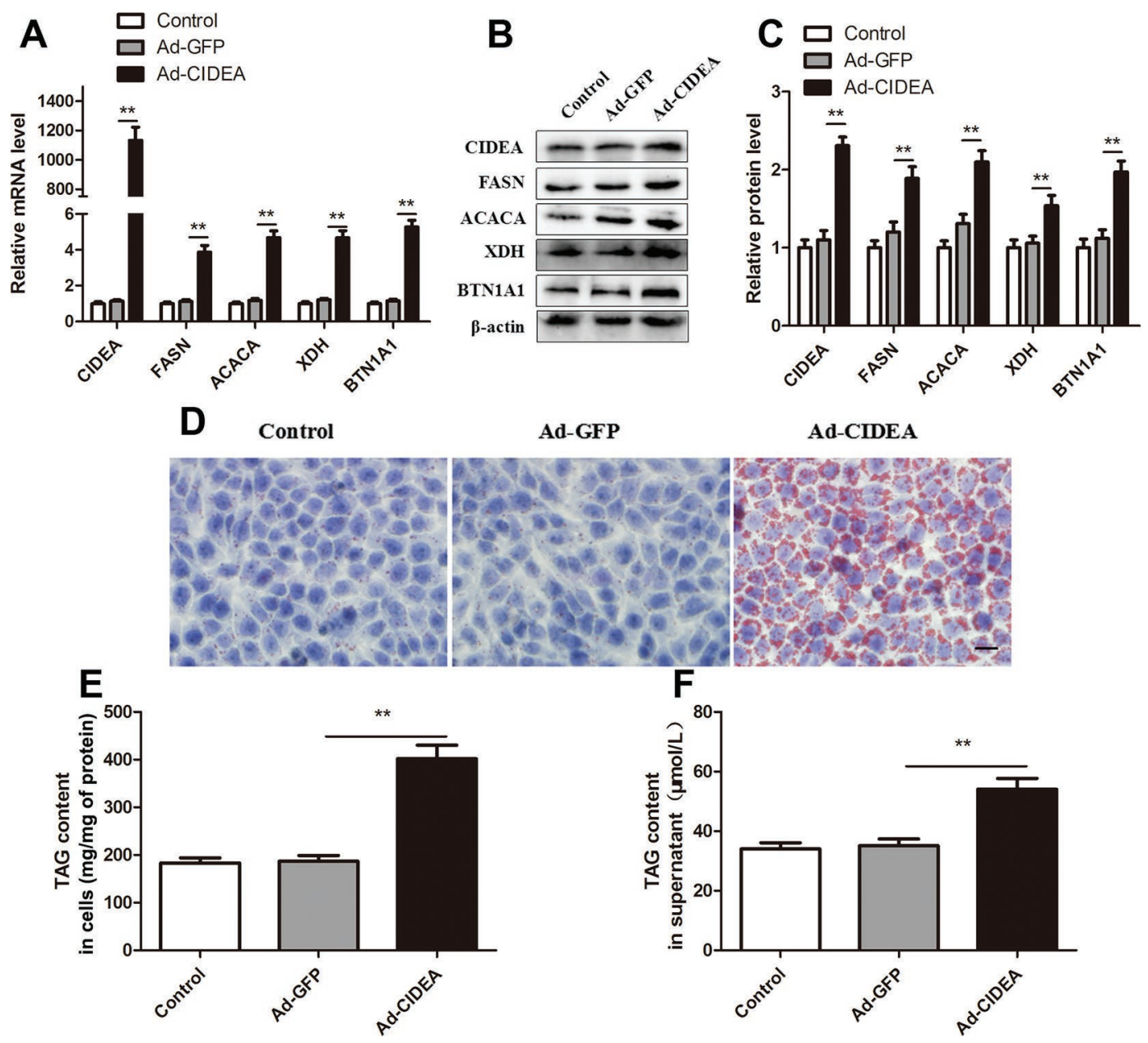

Ad-CIDEA
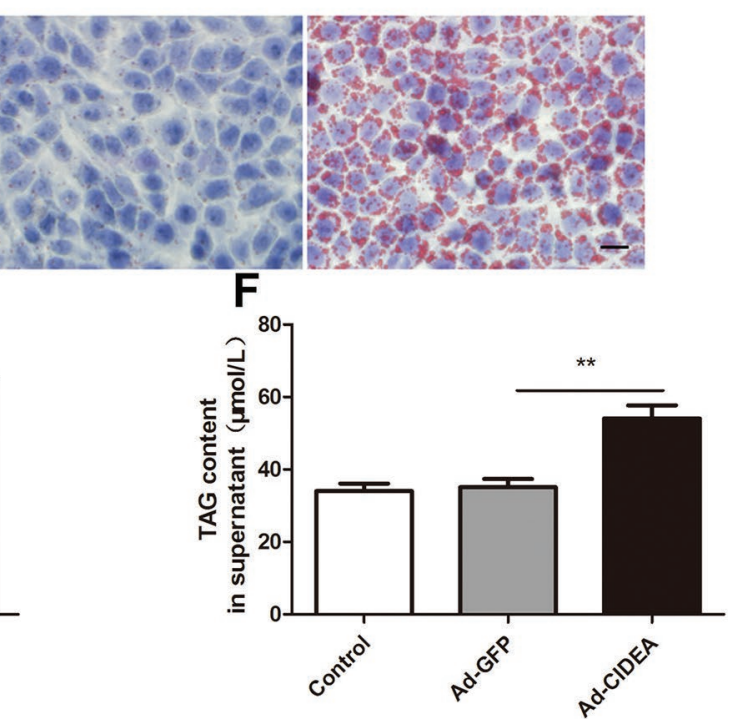

Figure 2. The effect of CIDEA overexpression on milk mat synthesis and secretion in bovine mammary epithelial cells. The cells were divided into 3 groups as follows: control group (cells were cultured in DMEM/F12 without CIDEA overexpression adenovirus or empty adenovirus vector), empty adenovirus vector-green fluorescent protein (Ad-GFP) group (cells were infected with d-GFP for $48 \mathrm{~h}$ ). CIDEA overexpression adenovirus (Ad-CIDEA) group (cells were infected with Ad-CIDEA for $48 \mathrm{~h}$ ). (A) Relative mRNA abundance of $C I D E A, F A S N, A C A C A, X D H$, and BTN1A1. (B) Western blot analysis of CIDEA, FASN, ACACA, XDH, and BTN1A1. (C) Relative protein abundance of CIDEA, FASN, ACACA, XDH, and BTN1A1. (D) Representative Oil Red O staining, scale bar $=100 \mu \mathrm{m}$. (E) Content of triacylglycerol (TAG) in bovine mammary epithelial cells. (F) The content of TAG in the supernatant. The data of the control group were used to normalize the data of each treatment group. Comparisons among groups were calculated using a 1-way ANOVA with subsequent Bonferroni correction. The data presented are the mean $\pm \mathrm{SEM} ;{ }^{* *} P<0.01$.

crucial mediators of milk lipid secretion; $\mathrm{XDH}$ is enriched in the milk fat globule membrane (Ishii et al., 1995), whereas BTN1A1 specifically localizes to the apical membrane of milk secreting cells at sites of lipid secretion (McManaman et al., 2007). Abundance of BTN1A1 and XDH is increased in the mammary tissue of dairy cows during lactation by an average of 14 and 8 fold by d 60 postpartum, respectively (Bionaz et al., 2012b). In our study, the higher abundance of FASN, ACACA, BTN1A1, and XDH along with a greater milk fat content in cows with clinical ketosis suggested that enhanced synthesis and secretion of milk fat contributes to the elevation of milk fat content. The cows with clinical ketosis are characterized by high blood levels of
NEFA (Bobe et al., 2004). It is possible that exogenous NEFA (i.e., resulting from adipose lipolysis) would provide milk fat synthesis precursors in cows with ketosis, which further promotes milk fat synthesis and secretion. Such adaptations, along with the greater blood NEFA concentrations, partly explain the upregulation of FASN, ACACA, BTN1A1, and XDH in cows with clinical ketosis.

As the major energy component in bovine milk, milk fat represents approximately 3.5 to $5.2 \%$ of total milk composition and is predominantly composed of TAG, accounting for more than $98 \%$ of the total milk lipids (Risérus and Marklund, 2017). Typically, lipolysis and the mobilization of body fat account for $<10 \%$ of the 
fatty acids in milk fat (Bauman and Griinari, 2003). Dairy cows with clinical ketosis have high concentrations of NEFA resulting from adipose lipolysis (Wagner and Schimek, 2010; Kumar et al., 2015), which contributes to milk fat synthesis (Bauman and Griinari, 2003). Furthermore, NEFA can act as signaling molecules that can regulate lipid metabolic gene abundance (Jump et al., 2005). In our study, the upregulation of fatty acid de novo synthesis genes (FASN and $A C A C A)$ and milk fat secretion genes (BTN1A1 and $X D H)$ when exogenous NEFA were incubated with mammary epithelial cells confirmed those responses. In addition, the increase in TAG content in cultured mammary epithelial cells and supernatant in response to exogenous NEFA confirm their contribution to the elevation of milk fat content in cows with clinical ketosis.

Plasma NEFA concentrations are positively correlated with milk fat content (Pullen et al., 1989). In our study, the abundance of FASN and ACACA mediating de novo fatty acid synthesis was enhanced, both in clinically ketotic dairy cows with high blood concentration of NEFA and in mammary epithelial cells incubated with exogenous NEFA. From a regulatory standpoint it is noteworthy that sterol regulatory element-binding protein 1 (SREBP1), an important transcription regulator of lipogenesis in nonruminants, can directly regulate the expression of ACACA and FASN. In addition, Li et al., (2014a) found that stearic acid increased the expression of SREBP1, ACACA, and FASN and promoted TAG synthesis in dairy cow mammary epithelial cells. Therefore, we speculated that NEFA could activate SREBP1 followed by upregulation of ACACA and FASN transcription, which further enhances de novo fatty acid synthesis. The enzyme stearoyl-CoA desaturase 1 (SCD1) is also a target gene of SREBP1 (Li et al., 2014b); SCD1 is the primary enzyme involved in MUFA synthesis by introducing a double bond in the $\Delta^{9}$ position of myristoyl-, palmitoyl-, and stearoyl-CoA

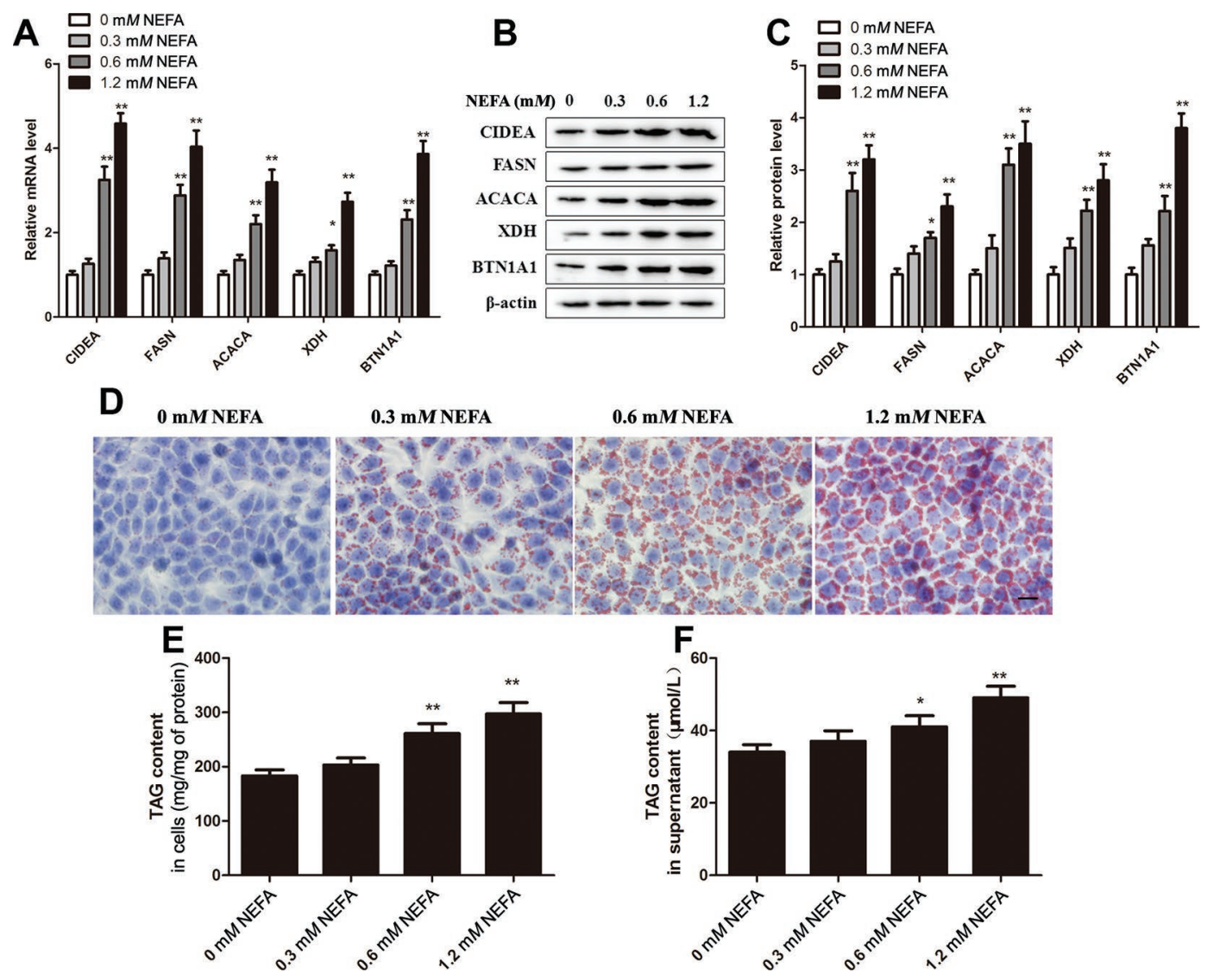

Figure 3. The effect of nonesterified fatty acids (NEFA) on milk mat synthesis and secretion in bovine mammary epithelial cells. Cells were treated with $0,0.3,0.6$, or $1.2 \mathrm{~m} M$ NEFA and $2 \%$ fatty acid-free BSA for $24 \mathrm{~h}$. (A) Relative mRNA abundance of $C I D E A, F A S N, A C A C A$, $X D H$, and BTN1A1. (B) Western blot analysis of CIDEA, FASN, ACACA, XDH, and BTN1A1. (C) Relative protein abundance of CIDEA, FASN, ACACA, XDH, and BTN1A1. (D) Representative Oil Red O staining, scale bar $=100 \mu \mathrm{m}$. (E) The content of TAG in bovine mammary epithelial cells. (F) The content of triacylglycerol (TAG) in the supernatant. The data of the $0 \mathrm{~m} M$ NEFA group were used to normalize the data of each treatment group. Comparisons among groups were calculated using a 1-way ANOVA with subsequent Bonferroni correction. The data presented are the mean $\pm \mathrm{SEM} ;{ }^{*} P<0.05,{ }^{* *} P<0.01$. 
(Ntambi and Miyazaki, 2003). Li et al. (2014a) also reported that SREBP1 mediated the stearic acid-induced SCD1 expression in dairy cow mammary epithelial cells. Thus, NEFA may regulate SCD1 through SREBP1 in mammary epithelial cells, subsequently promoting MUFA synthesis, which also would contribute to milk fat formation.

Formation of large lipid droplets in brown and white adipocytes is a key function of CIDEA in mice (Zhou et al., 2003; Puri et al., 2008). It is highly expressed in murine lactating mammary tissue and acts as a transcriptional co-activator regulating secretion of milk fat (Wang et al., 2012). Importantly, Yonezawa et al. (2009) detected greater abundance of CIDEA in mammary tissue of lactating versus dry dairy cows. Thus, the marked upregulation of CIDEA abundance in the mammary gland of cows with clinical ketosis underscored its involvement in the regulation of milk fat synthesis and secretion during ketosis. Yonezawa et al. (2009) reported that palmitate and stearate treatment significantly increased CIDEA expression in bovine mammary epithelial cells, which agrees with our findings that NEFA treatment increased the abundance of CIDEA in mammary epithelial cells. The mechanisms underlying the connections between fatty acids and CIDEA are still unclear. For instance, Zhou et al. (2012) found that CIDEA plays critical roles in promoting hepatic lipid synthesis in mice by acting as a sensor that directly responds to fatty acids. It could be possible that a similar mechanism exists in the mammary
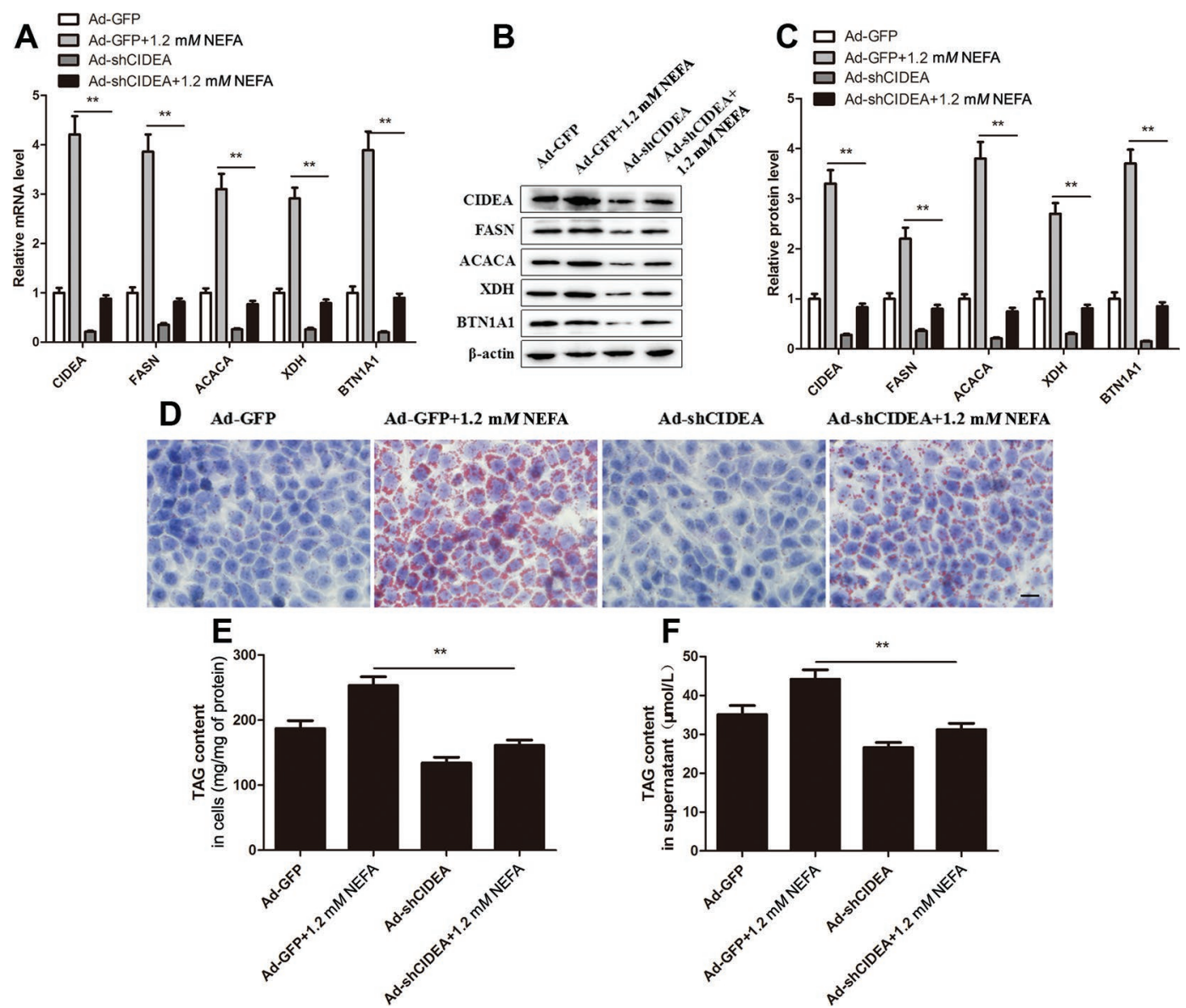

Ad-shCIDEA

Ad-shCIDEA+1.2 mM NEFA
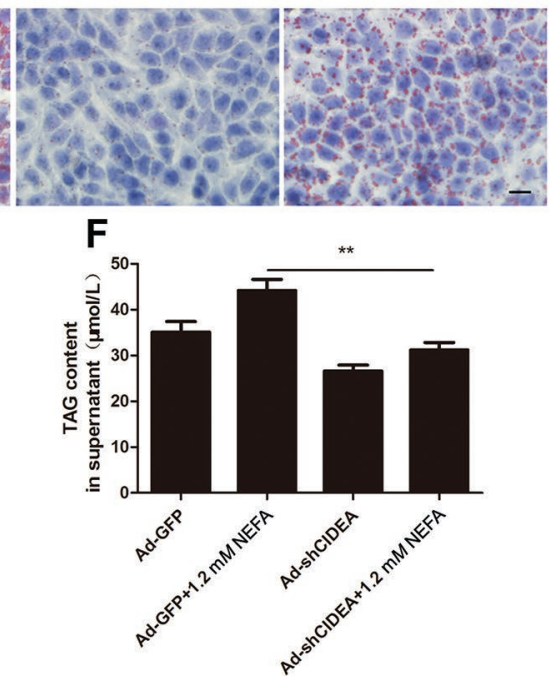

Figure 4. The effect of CIDEA silencing on milk mat synthesis and secretion in bovine mammary epithelial cells. The cells were divided into 4 groups as follows: empty adenovirus vector-green fluorescent protein (Ad-GFP) group (cells were infected with Ad-GFP for $48 \mathrm{~h}$ ), Ad-GFP + $1.2 \mathrm{~m} M$ nonesterified fatty acids (NEFA) group (cells were transfected with Ad-GFP for $48 \mathrm{~h}$ and then treated with $1.2 \mathrm{~m} M$ NEFA and $2 \%$ BSA for another $24 \mathrm{~h}$ ), CIDEA silence adenovirus (Ad-shCIDEA) group (cells were transfected with Ad-shCIDEA for $48 \mathrm{~h}$ ), and Ad-shCIDEA + 1.2 $\mathrm{m} M$ NEFA group (transfected with Ad-shCIDEA for $48 \mathrm{~h}$ and then treated with $1.2 \mathrm{~m} M$ NEFA and $2 \%$ BSA for another $24 \mathrm{~h}$ ). (A) Relative mRNA abundance of CIDEA, FASN, ACACA, XDH, and BTN1A1. (B) Western blot analysis of CIDEA, FASN, ACACA, XDH, and BTN1A1. (C) Relative protein abundance of CIDEA, FASN, ACACA, XDH, and BTN1A1. (D) Representative Oil Red O staining, scale bar $=100 \mu \mathrm{m}$. (E) The content of triacylglycerol (TAG) in bovine mammary epithelial cells. (F) The content of TAG in the supernatant. The data of the AdGFP group were used to normalize the data of each treatment group. Comparisons among groups were calculated using a 1-way ANOVA with subsequent Bonferroni correction. The data presented are the mean $\pm \mathrm{SEM} ;{ }^{* *} P<0.01$. 
gland of dairy cows. Therefore, the high abundance of CIDEA in the mammary gland of cows with clinical ketosis might be due to this protein's ability to serve as a sensor that directly responds to NEFA.

Work in nonruminants has indicated that CIDEA could regulate the expression of FASN and ACACA in the liver and adipose tissue (Zhou et al., 2012; Zhang et al., 2015). In the present study, overexpression of CIDEA increased the abundance of FASN and ACACA and increased TAG content in bovine mammary epithelial cells, indicating some control over the expression of FASN and ACACA. As evidenced by the significant downregulation of SREBP1 expression in the liver of CIDEA-deficient mice, Zhou et al. (2012) concluded that CIDEA could regulate the expression of SREBP1. Because SREBP1 binds both sterol regulatory element and E-boxes to activate the transcription of FASN and ACACA, it may serve as an intermediate in the molecular connections of CIDEA with downstream genes ( $F A S N$ and $A C A C A$ ) in the dairy cow mammary gland. The fact that overexpression of CIDEA increased the abundance of BTN1A1 and XDH in mammary epithelial cells and increased TAG content in culture supernatant is additional support for the role of CIDEA in promoting milk fat secretion. This protein acts as a transcriptional co-activator of CCAAT/enhancer-binding protein $\mathrm{b}(\mathrm{C} / \mathrm{EBPb})$ in the mouse mammary gland to control XDH expression and lipid secretion (Wang et al., 2012). Based on the report by Wang et al. (2012) and our results, we speculate that CIDEA may act as a transcriptional co-activator of $\mathrm{C} / \mathrm{EBPb}$ in dairy cow mammary gland to regulate the expression of milk fat secretion genes (BTN1A1 and $X D H)$.

Because knockdown of CIDEA prevented the increase in TAG concentration induced by NEFA, along with alterations in abundance of fatty acid de novo synthesis (FASN and $A C A C A$ ) and milk fat secretion genes (BTN1A1 and $X D H)$, availability of NEFA within mammary cells might be a signal regulating CIDEA. Therefore, we speculated that CIDEA mediates in part the development of NEFA-induced elevation of milk fat content during clinical ketosis. Further research is warranted to better understand the role of CIDEA in the mammary gland under normal and ketotic conditions.

\section{CONCLUSIONS}

Our in vivo and in vitro data indicate that NEFA can induce CIDEA expression in bovine mammary epithelial cells leading to upregulation of de novo fatty acid synthesis enzymes (FASN and ACACA) and milk lipid secretion proteins (BTN1A1 and XDH), thereby contributing to an increase in milk fat content in clinical ketosis.

\section{ACKNOWLEDGMENTS}

This work was supported by the National Key Research and Development Program (Beijing, China; grant no. 2016YFD0501206), National Natural Science Foundation of China (Beijing, China; grant nos. 31772810, 31672621 and 31572581), Jilin Province Science Foundation for Youths (Changchun, China; grant no. 20160520063JH), and Natural Science Foundation of Jilin Province (Changchun, China; Grant No. 20170101148JC). The authors declare no conflicts of interest.

\section{REFERENCES}

Adewuyi, A. A., E. Gruys, and F. J. van Eerdenburg. 2005. Nonesterified fatty acids (NEFA) in dairy cattle. A review. Vet. Q. $27: 117-126$.

Bauman, D. E., and J. M. Griinari. 2000. Regulation and nutritional manipulation of milk fat. Low-fat milk syndrome. Adv. Exp. Med. Biol. 480:209-216.

Bauman, D. E., and J. M. Griinari. 2003. Nutritional regulation of milk fat synthesis. Annu. Rev. Nutr. 23:203-227.

Bionaz, M., and J. J. Loor. 2008. Gene networks driving bovine milk fat synthesis during the lactation cycle. BMC Genomics 9:366.

Bionaz, M., K. Periasamy, S. L. Rodriguez-Zas, R. E. Everts, H. A. Lewin, W. L. Hurley, and J. J. Loor. 2012b. Old and new stories: Revelations from functional analysis of the bovine mammary transcriptome during the lactation cycle. PLoS One 7:e33268.

Bionaz, M., K. Periasamy, S. L. Rodriguez-Zas, W. L. Hurley, and J. J. Loor. 2012a. A novel dynamic impact approach (DIA) for functional analysis of time-course omics studies: validation using the bovine mammary transcriptome. PLoS One 7:e32455.

Bobe, G., J. W. Young, and D. C. Beitz. 2004. Invited review: Pathology, etiology, prevention, and treatment of fatty liver in dairy cows. J. Dairy Sci. 87:3105-3124.

Ding, Y., L. Yang, S. Zhang, Y. Wang, Y. Du, J. Pu, G. Peng, Y. Chen, H. Zhang, J. Yu, H. Hang, P. Wu, F. Yang, H. Yang, A. Steinbüchel, and P. Liu. 2012. Identification of the major functional proteins of prokaryotic lipid droplets. J. Lipid Res. 53:399-411.

Du, X., T. Shen, H. Wang, X. Qin, D. Xing, Q. Ye, Z. Shi, Z. Fang, Y. Zhu, Y. Yang, Z. Peng, C. Zhao, B. Lv, X. Li, G. Liu, and X. Li. 2018b. Adaptations of hepatic lipid metabolism and mitochondria in dairy cows with mild fatty liver. J. Dairy Sci. 101:9544-9558. https://doi.org/10.3168/jds.2018-14546.

Du, X., Z. Shi, Z. Peng, C. Zhao, Y. Zhang, Z. Wang, X. Li, G. Liu, and X. Li. 2017. Acetoacetate induces hepatocytes apoptosis by the ROS-mediated MAPKs pathway in ketotic cows. J. Cell. Physiol. 232:3296-3308.

Du, X., Y. Zhu, Z. Peng, Y. Cui, Q. Zhang, Z. Shi, Y. Guan, X. Sha T. Shen, Y. Yang, X. Li, Z. Wang, X. Li, and G. Liu. 2018a. High concentrations of fatty acids and $\beta$-hydroxybutyrate impair the growth hormone-mediated hepatic JAK2-STAT5 pathway in clinically ketotic cows. J. Dairy Sci. 101:3476-3487.

Duffield, T. F., K. D. Lissemore, B. W. McBride, and K. E. Leslie. 2009. Impact of hyperketonemia in early lactation dairy cows on health and production. J. Dairy Sci. 92:571-580.

Farr, V. C., K. Stelwagen, L. R. Cate, A. J. Molenaar, T. B. McFadden, and S. R. Davis. 1996. An improved method for the routine biopsy of bovine mammary tissue. J. Dairy Sci. 79:543-549.

Glascock, R. F., and V. A. Welch. 1974. Contribution of the fatty acids of three low density serum lipoproteins to bovine milk fat. J. Dairy Sci. 57:1364-1370.

Gross, J. J., F. J. Schwarz, K. Eder, H. A. Van Dorland, and R. M. Bruckmaier. 2013. Liver fat content and lipid metabolism in dairy cows during early lactation and during a mid-lactation feed restriction. J. Dairy Sci. 96:5008-5017. 
Heid, H. W., and T. W. Keenan. 2005. Intracellular origin and secretion of milk fat globules. Eur. J. Cell Biol. 84:245-258.

Ishii, T., N. Aoki, A. Noda, T. Adachi, R. Nakamura, and T. Matsuda. 1995. Carboxy-terminal cytoplasmic domain of mouse butyrophilin specifically associates with a $150-\mathrm{kDa}$ protein of mammary epithelial cells and milk fat globule membrane. Biochim. Biophys. Acta 1245:285-292.

Itle, A. J., J. M. Huzzey, D. M. Weary, and M. A. von Keyserlingk. 2015. Clinical ketosis and standing behavior in transition cows. J. Dairy Sci. 98:128-134.

Jedrzejczak, M., and I. Szatkowska. 2014. Bovine mammary epithelial cell cultures for the study of mammary gland functions. In Vitro Cell. Dev. Biol. Anim. 50:389-398.

Jia, H., X. Li, G. Liu, J. J. Loor, R. Buctrout, X. Sun, G. Li, X. Shu, J. Dong, Y. Wang, R. Zuo, Z. Wang, and X. Li. 2019. Perilipin 5 promotes hepatic steatosis in dairy cows through increasing lipid synthesis and decreasing very-low-density lipoprotein assembly. J. Dairy Sci. 102:833-846. https://doi.org/10.3168/jds.2018-15208.

Jump, D. B., D. Botolin, Y. Wang, J. Xu, B. Christian, and O. Demeure. 2005. Fatty acid regulation of hepatic gene transcription. J. Nutr. 135:2503-2506.

Kumar, P., V. K. Jain, A. Kumar, N. Sindhu, T. Kumar, G. Charaya Surbhi, S. Kumar, D. Agnihotri, and Sridhar.. 2015. Clinical and hemato-biochemical studies on fever of unknown origin in buffaloes. Vet. World 8:1225-1229.

Li, N., F. Zhao, C. Wei, M. Liang, N. Zhang, C. Wang, Q. Z. Li, and X. J. Gao. 2014a. Function of SREBP1 in the milk fat synthesis of dairy cow mammary epithelial cells. Int. J. Mol. Sci. 15:1699817013.

Li, X., Y. Li, W. Yang, C. Xiao, S. Fu, Q. Deng, H. Ding, Z. Wang, G. Liu, and X. Li. 2014b. SREBP-1c overexpression induces triglycerides accumulation through increasing lipid synthesis and decreasing lipid oxidation and VLDL assembly in bovine hepatocytes. J. Steroid Biochem. Mol. Biol. 143:174-182.

Loor, J. J., and J. H. Herbein. 2003. Reduced fatty acid synthesis and desaturation due to exogenous trans10,cis12-CLA in cows fed oleic or linoleic oil. J. Dairy Sci. 86:1354-1369.

Lundberg, K. L., P. C. Hoffman, L. M. Bauman, and P. Berzaghi 2004. Prediction of forage energy content by near infrared spectroscopy and summative equations. Prof. Anim. Sci. 20:262-269.

McManaman, J. L., T. D. Russell, J. Schaack, D. J. Orlicky, and H. Robenek. 2007. Molecular determinants of milk lipid secretion. J. Mammary Gland Biol. Neoplasia 12:259-268.

Ntambi, J. M., and M. Miyazaki. 2003. Recent insights into stearoylCoA desaturase-1. Curr. Opin. Lipidol. 14:255-261.

Ogg, S. L., A. K. Weldon, L. Dobbie, A. J. Smith, and I. H. Mather. 2004. Expression of butyrophilin (Btn1a1) in lactating mammary gland is essential for the regulated secretion of milk-lipid droplets. Proc. Natl. Acad. Sci. USA 101:10084-10089.

Ospina, P. A., D. V. Nydam, T. Stokol, and T. R. Overton. 2010. Associations of elevated nonesterified fatty acids and beta-hydroxybutyrate concentrations with early lactation reproductive performance and milk production in transition dairy cattle in the northeastern United States. J. Dairy Sci. 93:1596-1603.

Palmquist, D. L., P. F. Fox, and P. L. McSweeney. 2006. Milk fat: Origin of fatty acids and influence of nutritional factors thereon. Pages 43-92 in Advanced Dairy Chemistry. Volume 2: Lipids. P. F. Fox and P. L. H. McSweeney, eds. Springer US, New York, NY.

Petrov, P. D., N. Granados, C. Chetrit, D. Martínez-Puig, A. Palou, and M. L. Bonet. 2015. Synergistic effects of a mixture of glycosaminoglycans to inhibit adipogenesis and enhance chondrocyte features in multipotent cells. Cell. Physiol. Biochem. 37:1792-1806.
Pullen, D. L., D. L. Palmquist, and R. S. Emery. 1989. Effect on days of lactation and methionine hydroxy analog on incorporation of plasma fatty acids into plasma triglycerides. J. Dairy Sci. 72:49-58.

Puri, V., S. Ranjit, S. Konda, S. M. Nicoloro, J. Straubhaar, A. Chawla, M. Chouinard, C. Lin, A. Burkart, S. Corvera, R. A. Perugini, and M. P. Czech. 2008. Cidea is associated with lipid droplets and insulin sensitivity in humans. Proc. Natl. Acad. Sci. USA 105:7833-7838.

Qi, J., J. Gong, T. Zhao, J. Zhao, P. Lam, J. Ye, J. Z. Li, J. Wu, H. M. Zhou, and P. Li. 2008. Downregulation of AMP-activated protein kinase by Cidea-mediated ubiquitination and degradation in brown adipose tissue. EMBO J. 27:1537-1548.

Risérus, U., and M. Marklund. 2017. Milk fat biomarkers and cardiometabolic disease. Curr. Opin. Lipidol. 28:46-51.

Sun, X., X. Yuan, L. Chen, T. Wang, Z. Wang, G. Sun, X. Li, X. $\mathrm{Li}$, and G. Liu. 2017. Histamine induces bovine rumen epithelial cell inflammatory response via NF- $\mathrm{B}$ pathway. Cell. Physiol. Biochem. 42:1109-1119.

Torrens, J. M., J. M. Orellana-Gavaldà, M. Palou, J. Sánchez, L. Herrero, C. Picó, D. Serra, and A. Palou. 2014. Enhancing hepatic fatty acid oxidation as a strategy for reversing metabolic disorders programmed by maternal undernutrition during gestation. Cell. Physiol. Biochem. 33:1498-1515.

Wagner, S. A., and D. E. Schimek. 2010. Evaluation of the effect of bolus administration of $50 \%$ dextrose solution on measures of electrolyte and energy balance in postpartum dairy cows. Am. J. Vet. Res. 71:1074-1080.

Wang, M., B. Xu, H. Wang, D. Bu, J. Wang, and J. J. Loor. 2014. Effects of arginine concentration on the in vitro expression of casein and mTOR pathway related genes in mammary epithelial cells from dairy cattle. PLoS One 9:e95985.

Wang, M. Z., L. Y. Ding, C. Wang, L. M. Chen, J. J. Loor, and H. R. Wang. 2017. Short communication: Arginase inhibition reduces the synthesis of casein in bovine mammary epithelial cells. J. Dairy Sci. 100:4128-4133.

Wang, W., N. Lv, S. Zhang, G. Shui, H. Qian, J. Zhang, Y. Chen, J. Ye, Y. Xie, and Y. Shen. 2012. Cidea is an essential transcriptional coactivator regulating mammary gland secretion of milk lipids. Nat. Med. 18:235-243

White, H. M. 2015. The role of TCA cycle anaplerosis in ketosis and fatty liver in periparturient dairy cows. Animals (Basel) 5:793-802.

Yamdagni, S., and L. H. Schultz. 1970. Fatty acid composition of blood plasma lipids of normal and ketotic cows. J. Dairy Sci. $53: 1046-1050$

Yonezawa, T., S. Haga, Y. Kobayashi, K. Katoh, and Y. Obara. 2009 Saturated fatty acids stimulate and insulin suppresses CIDE-A expression in bovine mammary epithelial cells. Biochem. Biophys. Res. Commun. 384:535-539.

Zhang, M., S. Zhang, Q. Hui, L. Lei, X. Du, W. Gao, R. Zhang, G. Liu, X. Li, and X. Li. 2015. $\beta$-Hydroxybutyrate facilitates fatty acids synthesis mediated by sterol regulatory element-binding protein1 in bovine mammary epithelial cells. Cell. Physiol. Biochem. $37: 2115-2124$

Zhou, L., L. Xu, J. Ye, D. Li, W. Wang, X. Li, L. Wu, H. Wang, F. Guan, and P. Li. 2012. Cidea promotes hepatic steatosis by sensing dietary fatty acids. Hepatology 56:95-107.

Zhou, Z., S. Yon Toh, Z. Chen, K. Guo, C. P. Ng, S. Ponniah, S. C. Lin, W. Hong, and P. Li. 2003. Cidea-deficient mice have lean phenotype and are resistant to obesity. Nat. Genet. 35:49-56. 